\title{
ARE ESL/EFL SOFTWARE PROGRAMS EFFECTIVE FOR LANGUAGE LEARNING?
}

\author{
Vládia M. C. Borges \\ Universidade Federal do Ceará
}

\begin{abstract}
This study investigated the extent to which ESL/EFL software programs on the market develop language skills. A software evaluation instrument was used to evaluate fifteen ESL/ EFL software programs for the technological, pedagogical and individualization features that would account for the incorporation of Communicative Language Teaching (CLT) principles and an interactive approach to computer use in language teaching. Results indicated that only three programs incorporated more than $75 \%$ of the technological features, four programs incorporated more than $70 \%$ of the pedagogical features, and only one program contained more than $70 \%$ of the features that allow for individualization of instruction. Overall, only two programs incorporated more than $70 \%$ of all analyzed features. The analysis of the programs provided evidence that the differentiating factor in ESL software programs lies not only in their pedagogical orientation, but also in how they incorporate CLT principles and an interactive approach to computer use into their design.
\end{abstract}


Keywords: ESL/EFL software programs; Communicative Language Teaching; Interactive Approach to computer use in language learning.

\section{Introduction}

In recent years there has been a great deal of interest in using computers for language teaching and learning. Little more than a decade ago, the use of computers in the language classroom was of concern only to a small number of specialists (Warschauer, Shetzer, \& Meloni, 2000). However, with the advent of multimedia computing and the Internet, the role of computers in language instruction has now become an important issue confronting large numbers of language teachers and researchers throughout the world (Beatty, 2003).

Currently, advocators of computer assisted language learning - CALL - argue that software programs can: (a) provide realistic, native-speaker models of the language in a variety of media, (b) offer a language learning curriculum, (c) do a needs assessment, (d) determine the best next step for the learner and provide practice with that skill area, (e) record what the student has done, along with an evaluation, and (f) be available at any hour and require no additional pay or benefits (Chapelle, 2001).

A number of high-end packages have attempted to come as close as possible to meeting those needs in terms of English language teaching. What distinguishes these high-end packages from many other multimedia programs is that they include a curriculum, not just distinct elements for practice (Meskill, 2002). However, the quality of the curriculum and its relevance to the target learners is not yet clearly established. 
Another similarity in these high-cost products is their relative immutability. There is little or no provision for teachercustomized content, because it would be difficult to incorporate teacher-generated lessons into a fixed curriculum. Some of the programs have teacher's guides and suggest ways to incorporate lessons into a regular classroom, but the assumption is that students will tend to work through the computer-based curriculum independently of what goes on in the classroom. The most stand-alone of these programs also tend to be the least openended in the activities they provide; a human teacher is needed to evaluate free responses, where they occur (Meskill, 2002). In general, software programs offer practice in a variety of skills, but without extensive management systems or prescriptive curricula. Most expect the learner, often with the help of a teacher, to decide what skills to work on and what media to use. These can range from comprehensive to limited, very expensive to quite affordable (Weasenforth, Meloni, \& Biesenbach-Lucas, 2005).

Where the computer is not seen as a substitute for a teacher, schools may purchase smaller, more limited, but more flexible software that individual teachers will use as an add-on to instruction or that will be placed in libraries as language references and resources. Language teachers have been especially blessed in this category of software, with hundreds of programs available. The benefits of adding a computer component to language instruction are many, and include: (a) multimodal practice with feedback, (b) individualization in a large class, (c) pair and small group work on projects, either collaboratively or competitively, (d) the fun factor, (e) variety in the resources available and learning styles used, (f) exploratory learning with large amounts of language data, and (g) real-life skill-building in computer use (Egbert, \& Hanson-Smith, 1999). 
One of the great benefits of the growth of multimedia is that software vendors (and language teachers) no longer feel bound to grammar practice as the main goal of computer use in the language classroom. While the process has taken longer in the foreign language arena than in English language teaching, the movement toward communicative teaching with computers is clearly taking place. There are still a great many grammar and vocabulary drill programs available, but at least the vocabulary programs have started to be contextualized and to incorporate graphics, audio recording and playback, and video (Meskill, 2002). Drills do have a place in language learning, particularly in the first stages of vocabulary acquisition where giving the same information in multiple modes, such as visual plus aural plus textual, enhances recognition and recall. More sophisticated error-checking can provide students real help in the feedback they receive, directing them to further practice or moving them to the next stage (Weasenforth, Meloni, \& Biesenbach-Lucas, 2005). Those who do need extra help with those aspects of language that improve with practice can use small, focused programs to give them additional time and assistance outside of regular class time.

The changes or lack thereof over time in what teachers and students do with and think about technology provide a perspective in viewing the role of computers in education, and maybe even some ideas about activities that motivate students and encourage learning. Proof is elusive, but as more research is performed, the role technology plays in language learning becomes clearer.

During the five decades of CALL development, materials have gone from an emphasis on basic textual gap-filling tasks and simple programming exercises to interactive multimedia presentations with sound, animation and full-motion video. But this progress has not been purely linear and, "in terms of pedagogy, the new and improved 
have not always replaced the old and tired. Instead, many programs being produced today feature little more than visually stimulating variations on the same gap-filling exercises used 40 years ago" (Beatty, 2003, p. 11). There appears to be a substantial gap between what computer technology can do to support language learning and the way actual software programs provide for language learning. Therefore, there might be programs on the market which claim to be interactive but their design may lag behind ESL pedagogy The Communicative Approach to Language Teaching. Although a review of the literature on ESL/EFL computer programs supports a pedagogical use of computer tools, the incorporation of more updated theories of learning in the elaboration of ESL computer programs seems to be rather complex and difficult to achieve.

The problem is that the commercial software industry is the major creator of the most commonly used CALL learning materials. Although it can be argued that the same is true for traditional publishing, the relationship between educators and print publishers is of a more symbiotic nature, particularly as governments, schools and universities tend to have syllabi to which publishers' materials must conform. The same is seldom true for CALL materials, for the simple reason that there are not enough CALL materials to choose from and the market is not yet as competitive or adaptable to local needs, especially considering the high costs of producing a CD-ROM, a process more akin to producing a movie than publishing a textbook. Also, since most software programs are designed for individual use, little attention is given to teachers' needs. Overall, changes in CALL tend to be governed more by advances in technology than by pedagogical insights (Beatty, 2003).

Consequently, it seems useful to identify meaningful ways of analyzing CALL material so that the characteristics associated with 
high quality interactive CALL material can be identified, articulated, and refined. Although there are many ways to evaluate and critique CALL programs, for in one sense their evaluation is analogous to the evaluation of a new textbook or other instructional resources, little attention has been given to whether particular programs effectively promote second language learning according to the principles of Communicative Language Teaching.

If CALL software packages are to be properly evaluated and matched with learning needs, there must be a set of criteria to be taken into consideration in their evaluation. Because this research is concerned with criteria for the evaluation of CALL software programs designed for ESL/EFL learning, it has used a validated evaluation instrument that encompassed the principles of Communicative Language Teaching and an interactive approach to computer use for language learning (Borges, 2011) in order to examine the following questions:

1. Do ESL/EFL software programs incorporate the technological features associated with interactive CALL?

2. Do CALL programs present technological features that allow for individualized instruction?

3. Do ESL/EFL software programs incorporate the teaching principles of the principles of Communicative Language Teaching?

In sum, to what extent do CALL programs create environments that develop language skills according to the Communicative Approach to Language Teaching and an interactive approach to computer use for language learning? 
Traditionally, much research on CALL (Light, 1993; Light, \& Mevarech, 1992; McLoughlin, \& Oliver, 1998) has focused on whether or not students learn better with a computer, and whether or not second/foreign language skills can be developed by a software program. The question now is no longer whether or not computers should be used to teach and learn language. Questions now include how computers should be used and how well software programs incorporate into their design what is known as best practices for language learning.

This study attempts to go beyond previous research which has investigated the advantages and disadvantages of using computers to develop specific language skills and to influence students' attitude toward language learning. Because CALL is an important aspect of many language-learning programs, it makes sense to be able to evaluate the types of programs which promote language development in second/foreign language learners.

Data gathered in this study will inform researchers about the features in software programs that effectively develop language learning according to Communicative Language Teaching principles and to an interactive approach to computer use in language learning.

\section{Review of the literature on the uses of multimedia for language learning}

Some of the major areas of software-related research in CALL have been the amount and types of interaction at the computer; effects of skill-building software, particularly writing; responses to multimedia; and attitudes toward computers and CALL.

The question of how students interact at and with the computer has been addressed in a number of studies, with Piper's (1986) being 
one of the earliest. In her study, as in many others, the type of software and the tasks teachers set for students had a large effect on the type and quality of student interaction with each other when working in pairs or small groups. Overall, software that requires a minimum of verbal interaction generates very little student participation, while having students write a joint report or produce something collaboratively results in a substantial amount of interaction.

Huang and Liu (2000) explored not only how students interact with computers, but also how they adjust themselves in learning English with the aid of multimedia computers. Their study presented two types of communication in the multimedia lab from the perspective of Communicative Language Teaching. First, Communicative Language Teaching in the multimedia lab presented a large impact on student-teacher communication. The studentteacher communication seemed to be blocked to some extent by the layout of the multimedia lab. The physical distance enlarged the psychological distance. The two-way communication between the teacher and the students turned into the one-way teacher to student communication. Second, student-computer communication was relatively new to students. For most of the students, it was the first time for them to take so much time "talking" to a computer. Students had to learn how to communicate with the computer so that they knew what move they should make next. They also noted that, because a multimedia lab is far larger than a traditional classroom, the teacher needed to talk to students through the broadcasting system. The "intimacy" between the student and the teacher was consequently gone. Nevertheless, Huang and Liu pointed out that the multimedia lab offered the opportunity for students to visualize the situation. The computer software created a virtual world that was very similar to the real world. 
A study by Brett (1997) also investigated students' reactions to the use of multimedia, their attitudes to its learning efficacy and their attitudes to multimedia as an independent study tool. Following the use of the CD-ROM English for Business 1 with a sample of 107 undergraduates, a questionnaire was administered. The questionnaire probed general reactions to the use of multimedia, attitudes to its learning efficacy and attitudes to multimedia as an independent study tool. Data on learner comparisons between multimedia and conventional learning tools were also collected and the statistical associations between types of learners and particular attitudes calculated. The results indicated strongly favorable attitudes toward multimedia, and that it delivered a high quality independent learning experience. Implications are that multimedia has a beneficial role to play in the curriculum and may have potential to facilitate effective language learning; may motivate; is useful for self-access; and may supersede other language learning. Questions regarding student attitudes toward computers seem to be part of most studies, including many of those cited here. Students tend to like using computers, even when they may not make much progress (Stenson, Downing, Smith, \& Smith, 1992) - and when they may feel that computers do not necessarily improve their language learning (Schcolnik, Abarbanel, Friedler, Heyman, \& Tsafir, 1996).

Another area with a great amount of research on multimedia uses for language learning has focused on the development of specific language skills. For example, research on writing has traditionally explored how students felt about and performed with word-processors. Daiute's (1985) Writing and Computer set the stage for much of what teachers did with writing in the classroom, in the language arts as well as in foreign language teaching. Studies by Neu and Scarcella (1991) and Phinney (1991) found that 
students had positive attitudes toward writing with computers and less apprehension about writing. Thaipakdee (1992) found better attitudes toward writing with computers which led to the improvement of writing skills. More recent research on writing includes the study of email correspondence as a way of improving motivation and writing skills (Kelm,1995; Sotillo, 2000; Sullivan \& Pratt,1996; Warschauer, 1995).

One skill area where research has more recently begun is listening, probably because sound-capable computers were not in widespread use until fairly recently. However, there have been a number of studies focusing on the use of multimedia for developing listening comprehension. Brett (1996) carried out investigations into the affective domain of multimedia for listening skills and also into the quantitative gains afforded to listening comprehension by the use of multimedia. He studied the initial attitudes and reactions to the use of video based CD-ROMs for listening comprehension by 107 undergraduates. He found overwhelming support for the technology. Results showed favorable attitudes: learners believed they could learn effectively from multimedia and believed that it delivered a high quality independent learning experience.

Brett (1997) has also investigated listening performance in a computer-based multimedia environment. He compared the learner success rates on comprehension tasks and follow up cloze tests while using (1) media of audio and video with pen and paper to and (2) multimedia. Results of learners' performance on the tasks in the different situations showed more effective comprehension and recall while using multimedia than audio or video plus pen and paper. The reasons proposed for the greater success rates were: efficiency of delivery with all the media for input and learning tasks in one place, the effect of the on-line feedback in guiding learners to correct 
interpretations of the message, and students' constant monitoring of their interpretations of the message.

Jakobsdottir and Hooper (1995) studied listening with a unique focus. They used a modified total physical response method to gauge elementary students' listening skills. Students selected buttons and graphics on a computer screen in response to commands given in Norwegian. They concluded that providing congruent text with spoken words facilitated acquisition of listening skills, at least for these elementary students.

Some research on the uses of multimedia for the development of specific language skills has focused on the uses of CALL to develop reading comprehension skills. Two aspects of reading received the most attention in research: the use of glossing formats and the acquisition of vocabulary.

Glossing formats are aids used to help the reader understand the meaning of words and phrases, and the effects of various forms of glosses were studied (Adair-Hauck, Willingham-Mclain, \& Youngs, 1999; Lomicka, 1998; Nagata, 1999). The second aspect that received major attention was the acquisition of vocabulary for supporting reading comprehension (Chun \& Plass, 1996; Grace 1998, 2000; Kang \& Dennis, 1995; Liu, 1995; Liu \& Reed, 1995). These studies showed that computer-supported glossing formats proved to be helpful in developing reading proficiency and that vocabulary learning could be greatly enhanced by incorporating a variety of annotations for words through visual media in multimedia technology.

In studying the use of multimedia for the acquisition of vocabulary as a way to enhance reading skills, Chun and Plass (1996) found positive effects for the learning of German vocabulary through a multimedia program with annotations combining pictures and text more effective than those with video and text. A study by Liu and Reed 
(1995) investigated the effect of the use of multimedia courseware on the learning and retention of eighty items of vocabulary. Their study used four, ten-minute clips of the movie "Citizen Kane", designed for language learning. The new design made available to learners the text of the clips with twenty target vocabulary items highlighted. These items were linked hypertextually to a definition, a part of speech, example sentences, video context and relationships of each word. There was also the option to do exercises using the vocabulary. Results showed a positive effect of the multimedia materials on posttest scores and on a retention test for all ability levels.

Some studies have investigated how technology could be used to promote speaking skills (Derwing, Munro, \& Carbonaro, 2000; Liaw, 1997, and Wachowicz and Scott, 1999). Liaw's (1997) research described a group of students using computer books and the conversations that took place as they read them. The study found that, as the students became more prolific readers, their discussions shifted from dealing with technological difficulties to the content of the books.

Wachowicz and Scott (1999) reviewed three levels of speechinteractive learning activities in selected commercial products: activities for vocabulary development, conversational practice, and pronunciation. Their review suggests that the effectiveness of speech-interactive CALL is determined less by the capabilities of the speech recognizer than by (a) the design of the language learning activity and feedback, and (b) the inclusion of repair strategies to safeguard against recognizer error. Wachowicz and Scott (1999) concluded that the approach seen in many pronunciation activities - "Repeat, imitate, get corrected by your teacher" - reflected dated pedagogical practices. At times, the computer is visualized as a high-quality tape recorder. 
A number of studies on the uses of multimedia for language learning have dealt with various learning strategies that could be enhanced using technology. These studies focused on: computer instruction in grammar over teacher instruction (Nutta, 1998); students working in pairs or alone (Chang \& Smith, 1991); autonomy (Sciarone \& Meijer, 1993); student interactions (Meskill, 1993); comparisons between using and not using multimedia or intelligent computer instruction (Nagata, 1997; Soo \& Ngeow, 1998); different modes of instruction to encourage linguistic, metacognitive, socioaffective, and academic skills (Kasper, 2000, and Plass, Chun, Mayer, Leutner, 1998). Chang and Smith (1991) compared students working in pairs in front of the computer and students working alone and found no difference in language gains between the two groups. Meskill (1993) looked at interactions between native and nonnative English speakers, and found a tendency for conversation to be dominated by the native speakers.

Other studies compared classroom performances with or without the use of multimedia (Nagata, 1997; Soo \& Ngeow, 1998), and found that different learning situations required different pedagogical approaches. The teacher in a multimedia environment needed to assume the role of a facilitator or resource advisor and may have had to dedicate more time to one-on-one-teacher-student interactions.

More recently, interactive video research has provided some of the first results about multimedia effectiveness in language teaching. Verano's (1989) study of interactive video for Spanish teaching, for example, found that the more interactive the video worked, the more students retained. Liu (1995) found that computer-based hypermedia enhanced vocabulary learning, while Engelsberg (1997) had mixed results from a multimedia program. In Englesberg's study, students enjoyed the multimedia courseware a great deal for the first 
five weeks of the term but became increasingly dissatisfied and did not perform as well as time went on. As in other areas of effectiveness research, the variables here were complex.

A study by Brett (1997) investigated the effects of three learning support elements in a multimedia application: video, subtitles, and comprehension tasks to accompany the video text. Subjects were asked to watch a video clip accompanied by different combinations of media elements. These were: (a) video only; (b) video and subtitles; (c) video and tasks; and (d) video, subtitles and tasks. Following their use of the combinations of media, subjects wrote a summary of the video clip having been asked to reuse as much of the original language of the clip as they could. Subjects' transcripts were scored for cross matches with the idea units in the original text and for matches of strings of words ( 3 or more long) from the original text. In both categories subjects using the media combinations of video and subtitles scored highest, followed by the true multimedia experience group of video, subtitles and tasks. The video only group scored lowest on both counts. He concluded that although the addition of the multi elements improved comprehension and language reuse, full blown multimedia (video, tasks and subtitles) did not lead to highest comprehension and language reuse scores, maybe indicating that too many media in multimedia are distracting. Nevertheless, the majority of investigations of learning success through use of multimedia or Interactive Video Disc (IVD) reports learning gains.

In summary, a review of the literature on the uses of multimedia for language learning shows the potential strength of CD-ROM materials. Exploitation of real world CD-ROMs leads learners to engage with such authentic language materials. Another potential strength of CD-ROM materials is their ability to create a situation in which learners can interact with the learning materials and reference 
materials. The materials on CD-ROMs can be linked into courses, syllabi or assigned to learners for homework or as follow up activities to work undertaken in classroom sessions. Reference CD-ROMs can also be used by teachers, as a help in preparing lessons, and by students, as research materials. Learners working together around a multimedia PC can use the tasks, input, or information as a basis for group work, discussions and joint decision-making.

At the micro level of motivation, multimedia may motivate learners to attend to the input through its use of combined media. This amalgamated use of video, supported by subtitles with instantly accessible definitions of language items and through on-line tasks with synchronous feedback, may all collectively or individually motivate learners to attend. Video may add interest and increase comprehension; on-line tasks may provide motivational goals for attention. Such an environment and the learning support features, more than other learning tools, may motivate learners to attend to the input, because such learning supports may make the input more comprehensible and accessible. These learning supports may also motivate learners to "notice" and consequently understand features of the input (Gass, 1997; Gass \& Selinker, 2001). The features of the multimedia-delivered may well provide the forum for supporting, encouraging or motivating the use of meta-cognitive strategies such as "monitoring" and being able to evaluate their own performance.

Another area which underpins multimedia is that of autonomous and self-instructed language learning. Multimedia-delivered language learning environments are primarily designed to be used by learners studying alone. They can deliver authentic input, provide meaningful language learning tasks, deliver feedback on those tasks and can be manipulated according to the learning agenda of the user. Therefore they may have great potential in facilitating autonomous language learning. 
However, as argued by Huang and Liu (2000), the choice of appropriate computer software that fits into the setting of a multimedia lab is one of the keys to success. Consequently, choosing software programs appropriate for the goals, needs, and interests of the students is essential, and in order to be able to choose the right software it is necessary to be able to effectively evaluate software programs.

\section{Method}

The purpose of this study was to evaluate ESL/EFL software programs. In order to assess the extent to which Computer Assisted Language Learning software programs develop ESL/EFL skills according to: a) the Communicative Language Teaching principles, and b) an interactive approach to computer use for language learning, a validated evaluation instrument was used (Borges, 2011).

\section{Evaluation Instrument}

In order to analyze the selected software programs, a validated ESL/EFL software evaluation instrument was used (Borges, 2011). The instrument is divided into two parts: 1.The "Descriptive Analysis", which describes the technical and pedagogical orientation of the software programs based on the documentation; 2 . The "Critical Analysis", which assesses the extent to which software programs available on the market develop ESL/EFL skills according to the principles of the Communicative Approach and an interactive model of computer use for language learning.

The criteria used for the ESL/EFL software evaluation instrument were based on: (a) technological features associated with interactive 
CALL; (b) features of the Communicative Language Approach; and (c) technological features that allow for individualized instruction. The gathered criteria were grouped into three clusters encompassing desirable features of software programs for ESL/EFL learning: (a) Technological features; (b) Pedagogical features; and (c) Individualized-learning features.

The ESL/EFL Software Evaluation Instrument consisted of 55 questions grouped into three distinct categories: instructional attributes, media attributes, user-friendly attributes. The rating scale designed to answer all questions ranged from 1 (for low) to 4 (for high). Zero would be chosen when the feature was not present in the program. The higher the rating of a program, the more the program would be evaluated as having the potential to develop ESL/EFL skills according to the principles of Communicative Language Teaching and to an interactive approach to computer use for language learning.

The internal consistency tests (Cronbach's Alpha) and reliability tests to which the instrument was submitted indicate that the 55 items of the instrument represent specific and distinguishing attributes of software programs that can be used as yardsticks for measuring the incorporation of the Media, User-Friendly, and Instructional Attributes into the elaboration and design of software programs. The incorporation of these attributes can, in turn, account for the integration of the features of Communicative Language Teaching and an interactive approach to computer use for language learning into software programs.

\section{Materials}

The selection of software programs which were analyzed in this study followed these criteria: 
1. Software programs designed for teaching/learning all four language skills (listening, speaking, reading, and writing), because the principles of the Communicative Approach apply to the teaching and learning of all four skills.

2. Multi-level software programs, so that the development of language skills could be observed from one level to another.

3. Software programs designed for teaching/learning ESL or EFL to adolescents and adults. Children/elementary grade learners were not included because ESL teaching/learning for this age/ grade level also involves teaching/learning content area subjects.

Several databases were searched for the keywords ESL/EFL + software, and 76 different titles were identified. Eliminating dictionaries and grammar and pronunciation tutors, the list was reduced to 63 titles. Of these 63 titles, 40 were discarded because they referred to software for either specific purposes, e.g., Business English, English for Traveling, or elementary education, and/or were designed to teach just one level of language proficiency (either beginner, intermediate or advanced students), or developed only one language skill (either listening, speaking, reading or writing). The resulting list of 23 programs was compared to the listing of software programs posted by TESOL (Teachers of English to Speakers of Other Languages Organization), and five other programs not previously included were added.

A quick analysis revealed that some of the program titles were in fact either different language proficiency levels of the same program, or program packages containing some of the programs that were listed separately. In sum, the number of analyzed software programs 
was reduced from the 23 programs to 15 software programs that truly met the specified criteria for the selection of software programs for this study.

The following fifteen programs were analyzed by this researcher using the ESL/EFL software evaluation instrument: "Asterix", "ELLIS", "English Discoveries", "Issues in English", "Learn English", "Learn to Speak English", "Live Action Interactive", "Longman English Interactive", "Making Connections", "New Dynamic English", "Rosetta Stone", "Side-by-Side", "Talk Now", “Tell me More", and "Who's Oscar Lake?".

\section{Data Collection and Analysis}

Data were collected from the evaluation of the above-mentioned fifteen programs using the ESL/EFL software evaluation instrument. In order to evaluate the programs, this researcher went through the process of installing, running and analyzing each program. Several lessons at different language proficiency levels for each program were completely finished. In each of the analyzed lessons for each program, the researcher also took the role of a learner, going through presentations, doing the activities, quizzes, games, recording readings and pronunciation of words in each program's syllabus. Mistakes were purposefully made in different activities of each program in order to analyze how programs treated errors and provided feedback.

Notes were also taken during the evaluation of each program, and a form of the ESL/EFL software evaluation instrument was completed for each program at the conclusion of the process described above. When the fifteen programs were evaluated, data were organized and analyzed in the following way: 
1. Ratings for the items in the categories of Media Attributes and User-Friendly Attributes of the ESL/EFL software evaluation instrument were analyzed in order to determine the degree of incorporation of technological features by the ESL/EFL software programs. The ratings for the category of Media Attributes and the ratings for the category of User-Friendly Attributes were added together and the percentage of the total maximum rating for these two categories together was calculated.

2. Ratings for the items related to the programs' degree and type of individualized instruction were analyzed to determine the degree of incorporation of individualized-learning features by the ESL/EFL programs. The ratings for these items were added and the percentage of the possible maximum rating for these items was calculated for each program.

3. Each program's ratings for all the items in the Media Attributes category were analyzed, and the percentage of the possible maximum rating for this category was calculated for each program.

4. Each program's ratings for all the items in the User-Friendly Attributes category were analyzed, and the percentage of the maximum possible rating for this category was calculated for each program.

5. Ratings for the items in the Instructional Attributes category were analyzed in order to determine the programs' degree of incorporation of the Communicative Language Learning Principles by the ESL/EFL software programs. Ratings for the 
items in this category were added and the percentage of the possible maximum rating for the category was calculated for each program.

6. Ratings for each program for all the items in all categories of the evaluation instrument were added, and the percentage of the possible total ratings was calculated in order to determine the extent to which the ESL/EFL software programs created environments that developed language skills according to the Communicative Language Teaching approach and the sociointeractive CALL model.

7. Ratings for each program in the three different categories of the ESL/EFL software evaluation instrument - Media, User-friendly, and Instructional Attributes - were used to identify the type of features which each program, and/or most programs, met best and/or failed to meet.

8. Ratings for all the items in the ESL/EFL software evaluation instrument for each program were also compared across each category. The results of the analysis of the $15 \mathrm{ESL} / \mathrm{EFL}$ software programs are presented next.

\section{Results of the analysis of the programs}

Results are presented in three sections: Section one reports ratings for the programs with respect to the categories of Media and User-Friendly Attributes which are technological features associated with interactive CALL. In this section the ESL/EFL 
software programs were also evaluated as to how they provided for individualized instruction. Section two presents the ratings for the programs with respect to the category of Instructional Attributes, which are based on the teaching principles of the Communicative Language Approach. Section three presents the overall ratings for the programs and evaluates the extent to which the programs create environments that develop language skills according to the principles of Communicative Language Teaching and an interactive approach to computer use for language learning.

\section{Analysis of the Incorporation of Technological Features by the ESL/EFL Software Programs}

In order to analyze how the ESL/EFL software programs incorporated the technological features associated with an interactive CALL model, the ratings for the category of Media Attributes and the ratings for the category of User-Friendly Attributes were added together and the percentage of the total maximum rating for these two categories together was calculated.

Media Attributes include: how the program helps learners move through the content and sequence of activities, how the media technology differentiates feedback, how the integration of different types of media facilitates learning, and the degree and type of individualization of instruction the program provides. The items in the User-friendly Attributes relate to how the program is perceived as attractive, easy to follow, and/or motivating to learners and teachers. The User-friendly Attributes include: how the use of the program is made easy for learners, how attractive the media technology makes the program, and how the program motivates learning. 
Table 1 shows the overall ratings of the programs for the category of Media Attributes and for the category of User-friendly Attributes which together encompass the ESL/EFL software programs incorporation of technological features associated with an interactive CALL model.

Table 1: Ratings for the Categories of Media Attributes and UserFriendly Attributes and Total Rating for these Categories Together (totals and percentages of possible maximum rating for the categories together)

\begin{tabular}{llll}
\hline Programs & $\begin{array}{l}\text { Ratings for } \\
\text { Media } \\
\text { Attributes }\end{array}$ & $\begin{array}{l}\text { Ratings for } \\
\text { User- } \\
\text { friendly } \\
\text { Attributes }\end{array}$ & $\begin{array}{l}\text { Total } \\
\text { Rating }\end{array}$ \\
& \multicolumn{3}{l}{} \\
\hline Tell me More & 46 & 34 & $80(74.07 \%)$ \\
Ellis & 39 & 39 & $78(72.22 \%)$ \\
Issues in English & 35 & 31 & $76(70.37 \%)$ \\
Discoveries & 43 & 21 & $64(59.25 \%)$ \\
Longman English & 27 & 33 & $60(55.55 \%)$ \\
Interactive & & & \\
Making Connections & 28 & 22 & $50(46.29 \%)$ \\
Learn English Now! & 28 & 21 & $49(45.37 \%)$ \\
Dynamic English & 22 & 26 & $48(44.44 \%)$ \\
Talk Now! & 25 & 22 & $47(43.52 \%)$ \\
Asterix & 25 & 21 & $46(42.59 \%)$ \\
Live Action & 26 & 20 & $46(42.59 \%)$ \\
Learn to Speak English & 24 & 20 & $44(40.74 \%)$ \\
Side-By-Side & 20 & 22 & $42(38.88 \%)$ \\
Rosetta Stone & 21 & 14 & $35(32.40 \%)$ \\
Who’s Oscar Lake? & 20 & 15 & $35(32.40)$ \\
\hline
\end{tabular}


The overall rating for the categories of Media Attributes and User-Friendly Attributes together indicated that only three programs were rated higher than 70\% - "Tell me More," rated 74.07\% for the two categories together, "ELLIS," rated 72.22 for the two categories together, and "Issues in English", rated 70.32\% for the two categories together. Two other programs were rated above $50 \%$ for the categories together - "Discoveries" (59.25\%) and "Longman English Interactive" (55.55\%). All other programs were rated below 50\% for the categories together. The results indicated that most analyzed ESL/EFL software programs did not incorporate many of the technological features associated with an interactive CALL model.

Perhaps the strongest feature associated with the level of interactivity afforded by the analyzed computer programs is integration of media, although there are several limitations to how media is effectively integrated. Current ESL/EFL software programs classified by their vendors as multimedia generally fall into the broad definition of multimedia as the integration of text, images, sound, video and/or animations (a mode of presentation), and leave out the integration of hypermedia (a pedagogical perspective). Whereas multimedia refers to the use of a variety of media, hypermedia can be defined from the two words that make up the term - hyper means non-linear or random and media refers to information represented in many formats (Thompson, Simonson \& Hargrave, 1992). Hypermedia can be defined as an external associational memory where the technology provides assistance in organizing and accessing information. The advantage of hypermedia is the possibility for easy access to various links within a program; selected referents would be only a keystroke away. Although most analyzed programs used several types of media (multimedia), they unfortunately allowed for only a fixed linear path (leaving out the possibilities of hypermedia). 
The computer's potential to provide an interactive multimedia learning program is well-demonstrated in "Issues in English". Audio and text alternatives are provided for transcripts, help and some of the exercises and feedback. Graphics are used to convey language meaning in some of the transcripts and exercises at the lower levels. Hypertext is used to great advantage in video transcripts and in the writing and grammar sections, with hot-words linking to explanations of meaning or examples of language use.

"ELLIS" is another program that provides learners with as much visual, oral and auditory practice as possible. The program also effectively introduces students to the United States culture. The strategy of the program is to create a "real world" learning environment for each lesson that is relevant to the student's life through the presentation of a short video segment. The dialogue from the video segment is transferred to the computer screen where the student is guided through a series of learning activities that include listening vocabulary, phrases, grammar, culture and pronunciation. Lesson concepts and context are introduced via brief, high-quality video dialogues posing situations that students and their families are likely to face. From the video segment (which can be played as many times as the student likes), the English language learner can ask the computer to slow down the audio portion. Clicking on a turtle icon slows the pace. The ability to record and immediately compare one's intonation and phrasing to a native English speaker's is a particularly popular and useful way to practice the language (and recording to get closer to the model is just fine by the software). Although "ELLIS" presents itself as a complete integrated multimedia system boasting student placement, record keeping, interactivity, integrated video, pronunciation practice, grammar instruction and practice, student 
voice recording and playback capability, vocabulary practice, and cultural instruction, it lacks significant hypermedia integration.

"Longman English Interactive" is a good example of perfect integration of multimedia with little use of hypermedia. Materials are presented through video, audio, animated texts, and regular text. The video has high resolution and its sound is clear and in sync with the images. Students can view a video clip as often as they want and they can easily play a segment that they want to view by clicking a bar underneath the video. Animated texts keep learners' attention and are appealing to visual learners because they highlight grammar and pronunciation points visually.

Finally, "Dynamic English" is a perfect example of the level of multimedia integration into most programs. The screen design is easy to manage because of its simplicity. The lessons use simple illustrated graphics to convey meaning and to support the spoken text through schematic inference. Students are encouraged to concentrate on the main information being conveyed before testing their understanding through a variety of activity types. The $\mathrm{ABC}$ button in the bottom right-hand corner allows the student to listen with or without the text. Certain words are highlighted and are hyperlinked to the glossary, which provides detailed grammatical explanations and examples of the word or structure in a sentence. Unfortunately there is no print facility for students to use this information for reference at a later date.

Other technological features associated with interactive CALL relate to user-friendly attributes of the programs. In this regard, the design of "Tell me More" provides an excellent layout for visual and auditory presentation. There are appealing musical tunes and rich colorful graphics in both the foreground and background. The quality of graphics in the video clips is excellent. They flow smoothly 
and easily without any interruptions. The quality of sound is also excellent due to the clarity of speech and authentic speech rate and accent. Having a speech rate that corresponds to that of native speakers is particularly suitable for advanced language learners who have already developed control over the language and need to learn to recognize speech at a faster and less controlled pace.

In "Live Action", the video screen provides quite intuitive icons for controlling the video, and the speaking activity screen also has easy to understand icons for controlling listening and recording functions. One constraint is that the rewind button for the video will always return the learner to the start of the video. Only with text displayed can the learner move to different sections of the text.

In "Longman English Interactive", the user-friendly highlights are the integration of an English-English dictionary, a glossary, culture notes, and a grammar reference book, which can be accessible throughout the program. The translated versions of the culture notes are available in Levels 1 and 2.

"New Dynamic English" includes a very comprehensive study guide and user's guide. The study guide provides detailed instruction on all aspects of the program. The user guide explains, in equal detail, how to set up and use the program. Additionally, the program is accompanied by an Instructor's Manual that includes the key vocabulary and grammar focus for each lesson and a selection of follow-up exercises.

"Issues in English" gives learners choice of content, level, task type, sequence, learning approach and pace, and thus gives learners greater control over their own learning to accommodate individual needs. Learners are also given the option to read video transcripts while listening, if this is their preferred learning strategy. While learners may find this a useful feature, it is possible that they are not 
always the best judges of the most effective strategies to use when such options are given. To encourage learners to listen first, before reading the text in the video activities, the author has built into the design of the program a 'no text' option as the default. However, for learners who are inclined to substitute reading comprehension for listening comprehension, more explicit guidance in appropriate strategies is likely to be required.

Some programs also have very positive user-friendly attributes. For example, "Longman English Interactive" has a bookmark function to allow users to automatically continue working from where they leave off. With the network version, each user is given a user name and password, which allows bookmarks to be kept within users' folders. Just like in the program "Longman English Interactive", one of "ELLIS's" best features is the ability of the software to provide assistance to the learner in the student's own native language. At the click of a mouse, learners can get help in their native language.

The overall analysis of how the ESL/EFL software programs incorporated technological features associated with interactive CALL should revisit the concept of interactive, since in the documentation of CALL programs this concept has become vague from overuse. In its simplest sense, interactive refers to a software program in which the learner has some small degree of choice, perhaps only in selecting answers to multiple-choice questions. Many of the analyzed software programs allowed for choices of question types, such as true/false, select an image or part of an image and move parts of picture or a sentence to correct positions. However, in more elaborate interactive programs, the learner should be able to enter into a simulated world, and make choices which would affect the direction of learning. Unfortunately, as the ratings for the Media Attributes and for the User-friendly Attributes 
indicated, most of the analyzed programs still incorporated the simplest sense of the concept of interactivity.

The analysis of the technological features of the programs also indicates that the more interactive the programs are the better they are for lab use than for individual use. One example of such a case is the program "Tell me More". It requires an expert to organize and install data for use. Besides, students need some time for experimentation or a brief introduction by an instructor to learn their way around the program.

Another example of a program which is a better fit for lab use is "English Discoveries". Like "Tell me More", it requires computer expertise to install the program, and an instructor to introduce learners to its content and features and to guide them in navigating through the program. Nevertheless, navigation through "English Discoveries" is fairly easy, since each learning section and working mode is presented by an icon. To get to a specific learning section users have to click on the respective icon. To exit the program from any screen users click on the Quit icon. However, because the program offers two different learning approaches-an open approach where users choose their own learning path, and three different kinds of prefabricated lessons, within which users have to follow the sequence of each lesson-navigation through its content and sequence might take a while to be mastered. An exception to this trend is the program "ELLIS," that, although also coming with good interactive features, is quite easy to be installed and runs well in individual computers.

Less interactive programs, like the "Longman English Interactive", are easier to install and perform well in individual computers. In fact, the installation of the program "Longman English Interactive" was completed easily without any problems, following the onscreen instructions. The software is easily uninstalled from the Windows 
Start Menu. "Longman English Interactive," in fact, is a good example of a program which helps learners move through its content and sequence with confidence and ease. The interface is clean, well organized, and consistent throughout the program. Navigation, help, and resources are placed at the top right of each screen and forward/ back arrows are placed at the bottom of the screen. Navigation is consistent and easy to use, and works properly. Learners can jump anywhere within a unit via a drop-down menu. They can also go to any specific part within a course from the Course Outline, which lists a detailed table of contents. Learners can also go to the previous and next pages by clicking the forward/back arrow buttons.

Other examples of programs which can be easily installed and run are "Live Action," "Asterix," "Learn English," and "Talk Now", although they all require the installation of Quick Time 5.0. On the other hand, "Who's Oscar Lake?" is an example of highly sophisticated software with simple installation features. This mystery game played in a virtual environment is fairly easy to open and navigate, although not user-friendly. However, the instruction manual and the on-line help are very useful for installation and starting the program.

Another feature associated with interactive CALL relates to how the media technology differentiates feedback. Computer-generated feedback can be done in the forms of: (a) positive evidence, which tells the learner that linguistic features in the input are possible in the target language (Krashen, 1977, 1994; Long, 1996; White, 1987); (b) negative evidence, which provides information to learners about what is not possible in the target language (Lightbown \& White, 1987; Long, 2005); and (c) implicit negative feedback, which can take the form of recasts-reformulation of a learner's ill-formed utterance - or negotiation of meaning. It is argued that recasts can provide implicit negative feedback, positive evidence, and enhanced salience 
through the juxtaposition of the original ill-formed utterance and the TL recast form (Leeman, 2000; Saxton, Kulcsar, Marshall, \& Rupra, 1998). In negotiation of form (Lyster, 1998; Lyster \& Ranta, 1997), instead of providing learners with the correct target language form, the software indicates to learners that they have produced an error and that the error requires repair. It is claimed that interactional modifications due to negotiation of meaning facilitate language learning (Long, 1996, 2005). Implicit feedback is, therefore, more closely associated with an interactive approach to computer use in language learning.

Unfortunately, in the fifteen analyzed programs most feedback took the form of positive evidence only. Generally speaking, the type of feedback provided by the analyzed programs needed to be improved in many aspects. Although not threatening, feedback given by the programs did not specify different types of errors, and very few programs offered feedback for both correct and incorrect answers.

Among all the analyzed programs, "Tell me More" offered the best feedback features. In "Tell me More", by default, there is no time limit for students to complete an activity; they simply click the $\langle\mathrm{OK}\rangle$ icon whenever they complete a given task. This time flexibility allows challenging activities without producing student frustration and anxiety. It is, however, possible for instructors to add a time limit on responses should it be required. As for feedback, the program provides visual feedback by highlighting mistakes in red and correct responses in green. Also, the automatic voice recognition feature of "Tell me More" is particularly useful in enabling students to improve their pronunciation and intonation skills. It includes waveform and pitch curve graphs that record the rising and falling intonation of students' voice and indicates the areas that need improvement. 
Moreover, it evaluates students' accuracy on a scale of 1 to 7 (7 being the highest) and allows them to repeat phonemes, words or sentences as many times as they wish by emulating male/female native speakers of English who have slight variations in accents and tones. This combination of audio-visual input and output quickly provides an efficient and effective model of error correction that improves pronunciation accuracy.

In "Live Action", response feedback, which is essentially limited to right/wrong answer processing, is complemented by program actions. For instance, in 9 of the 12 Interacts, the user hears a command and then drags an object to the proper place in the middle of the screen, where (if it is the correct object) a video is activated and the object is used as the command is carried out. In the Write activity, the dictation gives hints for errors until all have been corrected.

In "Longman English Interactive", learners can record their voice and listen to their conversation with the virtual partner - one of the characters from the video who speaks directly to the learner in a "Point of View" style. Learners can also view the transcript when listening to the conversation. The test sections have features that allow students to save their test scores, but it must be set up to do that at the beginning. For the network version, all student results are retained on a server via the teacher reporting tool.

Most other analyzed programs do not have a flexible anticipated response handling. Predetermined feedback is limited to an indication of correctness or incorrectness-there are no contextualized explanations linked to correct and incorrect answers. Explanatory information on teaching points is sometimes available in a separate information section, but is not contextualized and could easily be overlooked. 
In summary, the use of the ESL/EFL software evaluation instrument made it possible to analyze the user-technological interface in the programs. Results indicated that most of the software programs did not truly integrate the features of interactive CALL associated with the learner's interface. It seems that most program designers and publishers relied on the fact that the interface between learners and technology is highly correlated with how well users enjoy using a specific program, and put forth their best efforts in developing attractive software.

\section{Analysis of the Incorporation of the Principles of Communicative Language Learning by the ESL/EFL Software Programs}

In the evaluation of the incorporation of the principles of Communicative Language Teaching by the ESL/EFL software programs, the ratings obtained by the programs in the category of Instructional Attributes were analyzed. These Instructional Attributes include: the theory of language learning and teaching that underlies the program, how content is presented and sequenced, the type and quality of language-learning activities, the type of feedback provided, and how the program facilitates learning.

In order to make an overall analysis of how the programs incorporated the teaching principles of Communicative Language Teaching into their elaboration, each program's ratings for all the items in the category of Instructional Attributes were added and the percentage of the possible maximum rating for the category was calculated. In Table 2 the overall ratings of each program for the category of Instructional Attributes are shown. 
52 Vládia M. C. Borges, Are ESL/EFL software programs...

Table 2: Ratings of the Programs for the Category of Instructional Attributes (totals and percentages of possible maximum rating for the category)

\begin{tabular}{ll}
\hline Programs & Instructional Attributes \\
\hline Tell me More & $96(85.71 \%)$ \\
ELLIS & $88(78.57 \%)$ \\
Longman English Interactive & $82(73.21 \%)$ \\
Issues in English & $79(70.53 \%)$ \\
Discoveries & $67(59.82 \%)$ \\
Who's Oscar Lake? & $63(56.25 \%)$ \\
Side-By-Side & $61(54.46 \%)$ \\
Learn to Speak English & $60(53.57 \%)$ \\
Live Action & $56(50 \%)$ \\
Asterix & $54(48.21 \%)$ \\
Learn English Now & $53(47.32 \%)$ \\
Dynamic English & $47(41.96 \%)$ \\
Making Connections & $42(37.5 \%)$ \\
Talk Now! & $42(37.5 \%)$ \\
Rosetta Stone & $28(25 \%)$ \\
\hline
\end{tabular}

"Tell me More" was the program that obtained the highest overall rating for the category of Instructional Attributes - 85.71\%. The other three programs with high overall ratings for this category were "ELLIS" (78.57\%), "Issues in English" (70.53\%), and "Longman English Interactive" (73.21\%). "Discoveries," "Learn to Speak," "Live Action," "Side by Side," and "Who's Oscar Lake" were rated above $50 \%$. All the other programs were rated lower than 50\%. "Rosetta Stone" was the program with the lowest rating (25\%). 
The communicative approach of "Tell me More", the program with the highest rating for this category, is most apparent in the broad set of audio, visual and video materials that draw a clear distinction between fluency and accuracy. The dialogue exercises have been designed to promote fluency. The purpose is for students to use language without the intervention of a voice recognition feature to correct pronunciation and grammatical errors. For instance, in Seeing the USA, there is a dialogue that begins with "You are thinking of visiting the United States, what place are you going to visit?" Students can respond by stating, California, the East Coast, or Florida. If the student recognizes the picture of San Francisco on the left of the screen and responds by stating "California," a woman's voice says, "Ah San Francisco! Los Angeles! They're beautiful cities!." If the student responds by stating, the East Coast or Florida, however, the screen proceeds to the next question. It may seem that the computer's lack of response when the student's answer does not match the given picture tends to make the conversation artificial and somewhat mechanical. The fact that there is no right or wrong response, however, is consistent with a communicative approach that engages learners and prepares them to cope with a variety of everyday real-life situations that they may encounter in a foreign country.

The strategy of "ELLIS," the program with the second highest rating for the category of Instructional Attributes, is to create a "real world" learning environment for each lesson that is relevant to the student's life through the presentation of a short video segment. The dialogue from the video segment is transferred to the computer screen where the student is guided through a series of learning activities that include listening vocabulary, phrases, grammar, culture and pronunciation. Writing activities are provided in a companion workbook. Students are encouraged to speak English through the 
use of role play activities in which they assume the role of one of the actors in the video segment and insert their voice into the segment for playback and review. There are multiple practice activities that prepare students for their performance evaluations.

As the total ratings for the category of Instructional Attributes approaches $70 \%$, the level of integration of the principles of Communicative Language Teaching declines. The programs rated third and fourth in this category, although presenting many of the features of this approach to language teaching, also display some behaviorist features.

"Longman," the program with the third highest rating in the category of Instructional Attributes, is an integrated-skills program based on videos offering learners opportunities to learn and practice communicative skills and functional competencies that they need in the real world. It does in fact provide authentic contexts and plenty of information on American culture with the culture notes. Notwithstanding, it must be said that there is much greater focus on receptive than productive skills (a behaviorist feature).

"Issues in English," rated fourth in the category of Instructional Attributes, combines a variety of facilitative, interactive and instructional CALL methodologies which reflect elements of behaviorist second language acquisition theories. However, in using an interactive CALL methodology, the program is able to partially compensate for an absence of interpersonal interaction. The design of the program facilitates a communicative style of learner interaction with the computer, and negotiation of meaning through a variety of media including print, audio, visual and audio-visual. The inclusion of contextualized tutorial information for various teaching points, immediate feedback on most tasks, and learner control over learning paths and strategies set the scene for active participation in learning. 
However, the program would be more instructive if learners were more informed of the choices available to them in respect to learning paths and strategies.

Programs, such as "Live Action" and "Learn to Speak English", which rated below $70 \%$ and above $50 \%$ in the category of Instructional Attributes, might be considered communicative, because rather than teaching grammar or vocabulary out of context, propose authenticlooking videos of typical situations, and expect the learner to listen carefully, understand and repeat what native speakers say in those situations. However, they present no creative possibilities for the student, no collaborative and/or open-ended activities. Neither do they provide sociolinguistic information about the context of activities or detailed grammatical explanations.

As to content presentation and sequencing, to a greater or lesser degree of sophistication and with some minor variations, almost all units in the analyzed programs followed the same basic pattern: presentation, practice, and production. The only exception to this pattern was "Who's Oscar Lake?" Its game-like approach introduced the learner to the vocabulary and structures of the language as he/she played the game, trying to discover who Oscar Lake is.

In all programs, there was a variety of activity types such as drag and drop, multiple choice, fill in the blanks, dictation, cloze questions and speech recognition. However, most of them practiced the same type of grammar, vocabulary, listening, reading, speaking, and writing skills (usually much more in terms of decoding and lower level skills than in terms of higher-order thinking and problemsolving skills).

Among the analyzed programs, "Tell me More" had the widest range of activity types. For example, activities included: dialogue (in which the new vocabulary and language structure(s) are 
presented), sentence pronunciation, word pronunciation, phonetic exercises, picture association, word searches, word association, the right word, fill-in-the-blanks, words and topic, words and functions, grammar practice, mystery phrase, crossword puzzle, word order, sentence practice, dictation, glossary, video and questions, grammar explanation for the lesson, text transformation, and written expression.

The methodology underlying "Tell me More" subscribes to a communicative approach even though most of the activities were structure-based and involved simple picture/word association, contextual sentences and pure structure manipulation, etc. The activities were designed to foster language usage and resemble a series of everyday situations that might arise when learners attempt to communicate in English. In addition to video-clips, students interact with the computer and answer context specific questions that a friend, colleague, travel agent or flight attendant would ask them in real life.

In "Longman," as in most of the analyzed programs, there is much greater focus on receptive than productive skills. Speaking practice is not really speaking but rather practicing the scripted dialogue. Grammar exercises are just simple multiple-choice, drag and drop, or filling the blanks. Nevertheless, the sequence and organization of the software are pedagogically sound. Its variety of exercises helps learners stay motivated while using this program. The methodology underlying the program is a combination of exposure to authentic language usage, comprehensible input (Krashen, 1982), simulated oral communication practice, deductive grammar, plus drill and practice exercises.

"Longman" provides learners plenty of listening comprehension activities and is designed so that listening and speaking exercises 
are practiced before a Grammar section. Activities include comprehension and discussion of video clips, performing scripted dialogues, grammar drills, practicing functional expressions as presented in the Speaking section, practicing vocabulary items in the presentation of researched information.

Also, as in most programs, in "Live Action" exercises focus mainly on listening comprehension of imperative phrases and new vocabulary without any direct reinforcement of grammatical structures except for verb tense. The intent is to allow learners to focus on their listening and pronunciation without any pressure to speak. However, because of its Total Physical Response approach, activities always follow the same sequence in all the units: 1) Listen and watch, 2) Listen and do the actions watching the video clips or photos, and 3) Listen and do the actions without watching.

As mentioned previously, with a greater or lesser variety of activities, the programs cover the same language aspects: vocabulary, grammar, pronunciation, listening, reading, speaking and writing. In all programs, there are a lot of listen and repeat activities. In fact emphasis is placed on the role of repetition in acquiring good listening skills.

The comparison of the ratings for each program in the three different categories of the ESL/EFL software evaluation instrument - Media, User-friendly, and Instructional Attributes - helped to better identify the type of features which each program, and/or most programs, met best and/or failed to meet. The results of this comparison are shown in Table 3. 
Table 3: Total Ratings and Ratings for each Category of the Programs (totals and percentages of possible maximum rating for each category)

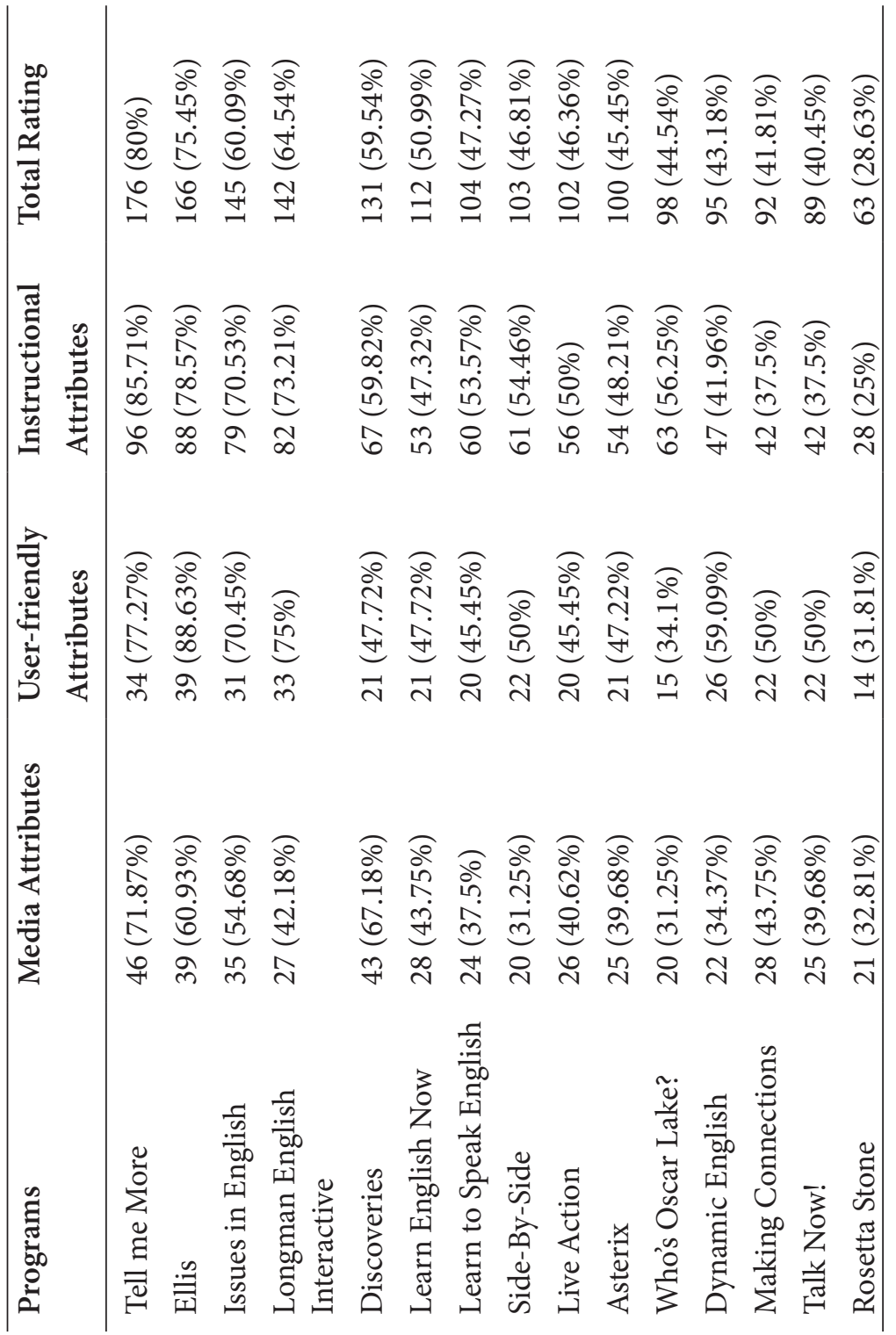


The analysis of the ratings across all categories for each program showed the weakest and the strongest set of features of each program. Media Attributes were the weakest features for most programs: "Asterix (39.69\%) "Dynamic English" (34.37\%), "ELLIS" (60.93\%), "Issues in English" (54.68\%), "Learn English" (37.5\%), Learn to Speak English" (37.5\%), "Live Action" (40.62\%), "Longman" (42.18\%), "Side-by-Side" (31.25\%), "Tell me More" (71.87\%), and "Who's Oscar Lake" (31.25\%). Among these programs, "Tell me More" was rated highest, while "Side-by-Side" was rated lowest. Media Attributes were, however, the strongest features for "Discoveries" (67.18\%) and "Rosetta Stone" (32.81\%). User-friendly Attributes were the weakest features only for "Discoveries" (47.72\%). These attributes were the strongest features for "Dynamic English" (59.09\%), "ELLIS" (88.63\%), "Longman" (75\%), and "Making Connections" (50\%). Among these programs "ELLIS" was rated the highest for User-friendly Attributes. Instructional Attributes were the weakest features for "Rosetta Stone" (25\%), "Talk Now" (37.5\%), and "Making Connections" (37.5\%), while these attributes were the strongest features for "Learn to Speak English" (53.57\%), "Live Action" (50\%), "Side-by-Side" (54.46\%), and "Tell me More" (85.71\%). Among these programs, "Tell me More" was rated the highest for Instructional Attributes.

However, this type of analysis did not yield much information about the potential of each program to teach the language according to the principles of Communicative Language Teaching and to an interactive CALL model, since for some programs even the strongest features were still rated very low overall. Therefore, ratings for each program were compared across each category.

In the category of Media Attributes, only "Tell me More" was rated above $70 \%$ (total ratings $=71.87 \%$ ). Three other programs "ELLIS," "English Discoveries," and "Issues in English" - were rated 
above 50\% in this category ("ELLIS" $=60.93 \%$, "English Discoveries" $=67.18 \%$, and "Issues in English" $=54.68 \%$ ). All the other programs were rated below 50\% in the category of Media Attributes.

In the category of User-friendly Attributes, four programs were rated above 70\% ("ELLIS" = 88.63\%; “Tell me More" = 77.27\%; "Longman" = 75\%; and "Issues in English" = 70.45\%). Four programs were rated above 50\% ("Dynamic English" = 59.09\%, "Making Connections" $=50 \%$, "Side-by-Side" $=50 \%$, and "Talk Now" $=50 \%$ ). The other programs were rated below $50 \%$ of the possible total ratings for the category of User-friendly Attributes.

In the category of Instructional Attributes, "ELLIS," "Longman," "Issues in English," and "Tell me More" were rated above $70 \%$ ("ELLIS" = 78.57\%, "Longman" = 73.21\%, "Issues in English" = $70.53 \%$, and "Tell me More" = 85.71\%). In this category, "Discoveries," "Learn to Speak English," "Live Action," "Side-by-Side," and "Who's Oscar Lake" were rated above 50\% ("Discoveries" $=59.82 \%$, "Learn to Speak English" = 53.57\%, "Live Action" = 50\%, "Side-by-Side" = $54.46 \%$, and "Who's Oscar Lake" $=56.25 \%$ ), while the others were rated below $50 \%$.

The ratings for the category of Media Attributes indicated that there is still a lot to be improved in these features - only one program was rated above $70 \%$, three above $50 \%$, and all the other ones below $50 \%$. The analysis of the results for the categories of User-friendly Attributes and Instructional Attributes indicated that while some programs still need to make improvements in their User-friendly Attributes (three programs were rated below $50 \%$ in this category), others have to make a great effort to make their Instructional Attributes better (three programs were rated below $50 \%$ in this category).

The analysis of the total ratings of each program (See Table 4 below) and of the ratings for the categories of each program (Table 
3) also indicated that "Tell Me More" was the program rated highest $(80 \%)$. However, this program was surpassed by "ELLIS" in the ratings for the features in the User-friendly Attributes - "ELLIS" was rated $88.63 \%$, and "Tell me More" was rated $77.37 \%$ for the same category. In fact, "ELLIS" had the highest rating for the category of User-friendly Attributes. For both programs - "Tell me More" and "ELLIS" - the weakest feature was the Media Attributes (71.87\% for "Tell me More," and 60.93\% for "ELLIS"). However, while for "ELLIS" the strongest feature was the User-friendly Attributes (88.63\%), for "Tell me More" the strongest feature was the Instructional Attributes (85.71\%). Nevertheless, these were the only programs which were rated above $75 \%$. The ratings for the other programs $(<70 \%)$ indicated that the programs did not meet at least three quarters of the criteria to be considered good examples of programs which have incorporated the principles of the Communicative age teaching Language Teaching and an interactive CALL model.

\section{Analysis of the Extent to which the ESL/EFL Software Programs Created Environments that Developed Language Skills according to the Communicative Approach to Language and an Interactive CALL Model}

In order to analyze the extent to which the ESL/EFL software programs created environments that developed language skills according to the principles of Communicative Language Teaching and an interactive approach to computer use for language learning, the ratings obtained by each program for all the items in all categories of the evaluation instrument were added, and the percentage of the possible total ratings was calculated. Results are shown below. 
Table 4: Total Ratings of the Programs

\begin{tabular}{lll}
\hline Programs & $\begin{array}{l}\text { Total } \\
\text { Rating }\end{array}$ & $\begin{array}{l}\text { Percentage of possible } \\
\text { maximum rating }\end{array}$ \\
\hline Tell me More & 176 & $80 \%$ \\
ELLIS & 166 & $75.45 \%$ \\
Issues in English & 145 & $66.09 \%$ \\
Longman English Interactive & 142 & $64.54 \%$ \\
Discoveries & 131 & $59.54 \%$ \\
Learn English & 112 & $50.99 \%$ \\
Learn to Speak English & 104 & $47.27 \%$ \\
Side-By-Side & 103 & $46.81 \%$ \\
Live Action & 102 & $46.36 \%$ \\
Asterix & 100 & $45.45 \%$ \\
Who's Oscar Lake? & 98 & $44.54 \%$ \\
Dynamic English & 95 & $43.18 \%$ \\
Making Connections & 92 & $41.81 \%$ \\
Talk Now! & 89 & $40.45 \%$ \\
Roseta Stone & 63 & $28.63 \%$ \\
\hline
\end{tabular}

The program "Tell Me More" had the highest overall rating (80\%), followed by "ELLIS", with an overall rating of $75.45 \%$. In fact these were the only programs rated above $75 \%$; all the other programs failed to meet at least three quarters of the features associated with Communicative Language Teaching and interactive CALL. Four other programs - "Issues in English" (66.09\%), Longman English Interactive" (64.54\%), "English Discoveries" (59.54\%), and "Learn English" (50.99\%) - met more than half of the features associated with Communicative Language Teaching and interactive CALL, while all other programs were rated below $50 \%$. 
The analysis of the programs provided evidence that the key differentiating factor in ESL software programs lies not only in their pedagogical orientation, but mainly in how they incorporate this orientation into their design. As previously stated, the criteria used in the elaboration of the ESL/EFL software evaluation instrument were based on the principles of the Communicative Language Teaching approach. Although all programs claim to incorporate communicative theories of language learning into their elaboration, they seem to have, to a greater of lesser degree, difficulty in elaborating activities that would develop language skills according to this approach. Communicative Language Teaching principles were incorporated in theory but not in practice in the programs. The syllabi of most programs presented characteristics of Communicative Language Teaching. However, the activities they presented were different from the type of activities that would aim to develop language skills for communicative purposes.

In effect, underneath some fancy graphics, sound effects, and an input device, the human-machine dialogue provided by these programs was essentially the same as the bare bones exchanges in the first stages of CALL. These programs, by virtue of more sophisticated visuals and possibilities for screen manipulations, were certainly more comfortable and empowering than the first commercial ESL/ EFL software programs. However, the fact that the current programs have become more attractive as processing power increased has not changed the elemental format for machine-user interaction: same dialogue, new interface.

In order to have truly incorporated the principles of the Communicative Language learning, the programs should have encouraged student-to-student interaction, and thus would have overcome their shortcomings as a means of communicative practice. 
In other words, explicit cues for paired student-student conversation could have been built into these software programs. All programs failed in cueing interaction by stimulating student exchange through visual and accompanying text prompts. Unfortunately, all the analyzed programs were designed for the single user, even when they came in lab versions. In the programs that allowed for lab use, the onus for orchestrating and prompting purposeful communication around these software programs was on the teacher.

\section{Final considerations}

The evaluation of the fifteen ESL/EFL software programs available on the market was an introspective study based on the results of the ratings for these programs using the ESL/EFL software evaluation instrument. The analyzed programs were not experimentally tested with ESL/EFL learners in an actual learning environment. Therefore, the discussion of the results of the analyses can only be interpreted in the light of the potential of the analyzed ESL/EFL software programs to develop language skills according to the principles of the Communicative Language Teaching and an interactive approach to computer use for language learning.

The scope of the study was limited to CALL software programs available on the market after 1990 since the interactive framework on pedagogical use of computers, adopted in this research, only began to be implemented in the 90s. Also, CALL programs available only online were not examined since these programs are usually kept online for a limited time. As the focus was to study how closely ESL/EFL software matches current theoretical understandings, no generalizations can be made about the extent to which online computer programs actually help develop language skills according 
to the principles of Communicative Language Teaching and an interactive approach to computer use for language learning.

The results of this investigation suggest specific areas for further research. Future studies should incorporate more diverse populations of ESL/EFL teachers, and include teachers from different countries. Besides, further studies should also use a larger sample of participants. Furthermore, the evaluation of ESL/EFL software programs should be done through the analysis of the whole programs, rather than just through the analysis of sample lessons in demonstration CD ROMs.

Further studies should also attempt to use the ESL/EFL software evaluation instrument to evaluate not only commercial software, but also software programs privately developed by universities and other language learning institutions. Also, future research should evaluate CALL programs available on the Internet.

Finally, other methods of investigating ESL/EFL software programs should be pursued. It would be relevant to first analyze an ESL/EFL software program using the ESL/EFL software evaluation instrument, and then have a group of ESL/EFL learners use this software program in order to see if the way actual learners respond to the program corresponds to the expectations of the program to potentially develop language skills according to the principles of Communicative Language Teaching and an interactive approach of computer use for language learning.

All studies on CALL programs should continue to document information on the effectiveness and limitations of computer technology for language learning. Additional information would help the development of CALL programs both in terms of their potential use for language learning as well as in terms of the areas that need further improvement. 
The results of this study encourage the development of alternative approaches for language learning through ESL/EFL software programs. The evaluation of the programs in this study indicated aspects of software programs that need refinement if they are to develop language skills according to the principles of Communicative Language Teaching and an interactive approach to computer use for language learning. Specifically, I recommend ESL/ EFL software programs be designed to:

1. Individualize instruction to match learners' needs, interests, and learning styles.

2. Allow for unexpected communicative situations, in which the learner would be able to interact without a script.

3. Develop competencies other than lexical and syntactical.

4. Provide feedback for expected and unexpected errors, and adapt the level of difficulty of the activities according to the responses given by the learners.

5. Specify the type of mistakes the learners make giving them the opportunity to self-correct their mistakes before providing the correct response.

6. Allow for collaborative work among learners and between learners and the instructor. 
7. Provide accessible information (background knowledge: linguistic, cultural, factual) necessary for the accomplishment of the activities and tasks.

In summary, the expansion of CALL undoubtedly provides new opportunities for learners of English to study from the convenience of their home (Warschauer, Shetzer, \& Meloni, 2000). However, the commercialization of CALL programs poses significant dangers. The types of CALL programs that are most effective for language learning involve a good deal of personal interaction, and are thus expensive to set up and teach (Warschauer et al. 2000; Feenberg, 1999). Thus quality educational programs involving extensive personal interaction face mounting economic competition from inexpensive but pedagogically unsound programs (Blumenstyk, 1999). Thus, ESL/EFL software program evaluation based on the principles of Communicative Language Teaching and an interactive approach to computer use for language learning plays an important role in ensuring that educationally relevant CALL programs can be chosen among the ones available on the market.

\section{References}

Adair-Hauck, B., Willingham-Mclain, L., \& Youngs, B. E. (1999). Evaluating the integration of technology and second language learning. CALICO Journal, 17, 269-306.

Beatty, K. (2003). Teaching and researching computer-assisted language learning. Great Britain: Pearson Education Limited.

Blumenstyk, G. (1999). The marketing intensifies in distance learning. Chronicle of Higher Education, April, A27.

Borges, V. M. C. (2011). Elaboration and validation of an ESL/EFL software evaluation instrument. Ilha do Desterro, 60, 305-364. 
Brett, P. A. (1996). 'Using multimedia: an investigation of learners' attitudes', Computer Assisted Language Learning Journal, 9.

Brett, P. (1997). A comparative study of the effects of the use of multimedia on listening comprehension. System, 25, 39-53.

Chapelle, C. (2001). Computer Applications in Second Language Acquisition. Cambridge, MA: Cambridge University Press.

Chang, K.-Y. R., \& Smith, W. F. (1991). Cooperative Learning and CALL/ IVD in beginning Spanish: An experiment. Modern Language Journal, $75,205-211$.

Chun, D., \& Plass, J. (1996). Effects of multimedia annotations on vocabulary acquisition. Modern Language Journal, 80, 183-198.

Daiute, C. (1985). Writing and computers. Reading, MA: Addison-Wesley.

Derwing, T., Munro, M., \& Carbonaro, M. (2000). Does popular speech recognition software work with ESL Speech? TESOL Quarterly, 34, 592602 .

Englesberg, R. (1997). An evaluation study of a multimedia package for learning English. CÆLLL Journal, 8, 15-20.

Egbert, J., \& Hanson-Smith, E. (1999) (Eds.), CALL environments: Research, practice, and critical issues. Alexandria, VA: TESOL

Feenberg, A. (1999a). Distance learning: Promise or threat. Retrieved May 30, 1999, from http://www-rohan.sdsu.edu/faculty/feenberg/TELE3.

Gass, S. (1997). Input, interaction, and the second language learner. Rowley, MA: Newbury House.

Gass, S. M., \& Selinker, L. (2001). Second language acquisition: An introductory course. Mahwah, NJ: Erlbaum.

Grace, C. A. (1998). Retention of word meanings inferred from context and sentence-level translations: Implications for the design of beginninglevel CALL software. Modern Language Journal, 82, 533-544.

Grace, C. A. (2000). Gender differences: Vocabulary retention and access to translations for beginning language learners in CALL. Modern Language Journal, 84, 214-224. 
Huang, S. J. and Liu, H. F. (2000). Communicative Language Teaching in a Multimedia Language Lab. The InternetTESL Journal, 6.

Jakobsdottir, S., \& Hooper, S. (1995). Computer-assisted foreign language learning: Effects of text, context, and gender on listening comprehension and motivation. Educational Technology Research and Development, 43, 43-59.

Kang, S.-H., \& Dennis, J. R. (1995). The effects of computer-enhanced vocabulary on achievement of ESL grade school children. Computers in the Schools, 11, 25-35.

Kasper, L. (2000). New technologies, new literacies: Focus discipline research and ESL learning communities. Language Learning and Technology, 4, 105-128.

Kelm, O. R. (1995). E-mail discussion groups in foreign language education: Grammar follow-up. In M. Warschauer (Ed.), Telecollaboration in foreign language learning. Proceedings of the Hawai'i symposium, Honolulu, HI, 58-61.

Krashen, S (1977). The monitor model for adult second language performance. In M. Burt, H. Dulay, \& M. Finocchiaro (Eds.), Viewpoints on English as a second language (pp. 152-161). New York: Regents.

Krashen, S. (1982). Principles and practice in second language acquisition. Oxford: Pergamon.

Krashen, S. (1994). The Input Hypothesis and its rivals. In N. Ellis (Ed.), Implicit and explicit learning of languages (pp. 45-77). London: Academic Press.

Leeman, J. (2000). Towards a new classification of input: An empirical study of the effect of recasts, negative evidence and enhanced salience on L2 development. Unpublished doctoral dissertation, Georgetown University, Washington DC.

Liaw, M. (1997). An analysis of ESL children's verbal interaction during computer book reading. Computers in the Schools, 13, 55-73.

Light, P. H. (1993). Collaborative learning with computers. In P. Scrimshaw (Ed.), Language, classrooms and computers (pp.155-159). London: Routledge. 
Light, P.H., \& Mevarech, Z.R. (1992). Cooperative learning with computers: an introduction. Learning and Instruction, 2, 155-159.

Lightbown, P., \& White, L. (1987). The influence of linguistics theories on language acquisition research. Language Learning, 37, 483-510.

Liu, M. (1995). Contextual enrichment through hypermedia technology: Implications for second language learning. Computers in Human Behavior, 11, 439-450.

Liu, M., \& Reed, W. M. (1995). The effect of hypermedia-assisted-instruction on second language learning. Journal of Educational Computing Research, 12, 159-175.

Lomicka, L. (1998). "To gloss or not to gloss": An investigation of reading comprehension online. Language Learning and Technology, 1, 41-50.

Long, M. (1996). The role of the linguistic environment in second language acquisition. In W. C. Ritchie \& T. K. Bhatia (Eds.), Handbook of research on language acquisition. Vol. 2: Second language acquisition (pp. 413468). New York: Academic Press.

Long, M. H. (2005). The delivery of negative feedback in naturalistic, classroom, and artificial environments. Proceedings of the UNTELE conference, Compiegne, France, 2005, 24-26.

Lyster, R. (1998). Negotiation of form, recasts explicit correction in relation to error types and learning repairs in L2 classrooms. Language Learning, $48,183-213$.

Lyster, R., \& Ranta, L. (1997). Corrective feedback and learner uptake: Negotiation of form in communicative classrooms. Studies in Second Language Acquisition, 19, 37-66.

McLoughlin, C., \& Oliver, R. (1998). Maximizing the language and learning link in computer learning environments. British Journal of Educational Technology $y_{2} 29,125-136$.

Meskill, C. (2002). Teaching and learning in real time: Media, technologies and language acquisition. Houston, TX: Athelson

Meskill, C. (1993). ESL multimedia: a study of the dynamics of paired student discourse. System, 21, 323-341. 
Nagata, N. (1997). The effectiveness of computer-assisted metalinguistic instruction: A case study in Japanese. Foreign Language Annals, 30, 187200.

Nagata, N. (1999). The effectiveness of computer-assisted interactive glosses. Foreign Language Annals, 469-479.

Neu, J. \& Scarcella, R. (1991). Word processing in the ESL classroom: a survey of student attitudes. In P. Dunkel (Ed.), Computer-assisted language learning and testing, 169-187. Rowley, MA: Newbury House.

Nutta, J. (1998). Is computer-based grammar instruction as effective as teacher-directed grammar instruction for teaching L2 structures? CALICO Journal, 16, 49-62.

Oliva, M., \& Pollastrini, Y. (1995). Internet resources and second language acquisition: An evaluation of virtual immersion. Foreign Language Annals, 28, 551-563.

Phinney, M. (1991). Computer-assisted writing and writing apprehension in ESL students. In P. Dunkel (Ed.), Computer-assisted language learning and testing, 189-204. Rowley, MA: Newbury House.

Plass, J. L., Chun, D. C., Mayer, R. E., \& Leutner, D. (1998). Supporting visual and verbal learning preferences in a second-language multimedia learning environment. Educational Psychology, 90(1), 25-36.

Saxton, M., Kulcsar, B., Marshall, G. , \& Rupra, M. (1998). Long term effects of corrective input and experimental approach. Journal of Child Language, 25, 701-721.

Schcolnik, M., Kol, S., Abarbanel, J., Friedler, J., Heymans, Y., \& Tsafrir, Y. (1996). Multimedia reference materials in advanced EFL courses: A project report. CÆLLL Journal, 6, 34-38.

Sciarone, A., \& Meijer, P. (1993). How free should students be? A case from CALL: Computer assisted language learning. Computers and Education, 21, 95-102.

Soo, K.-S., \& Ngeow, Y.-H. (1998). Effective English as a second language instruction with interactive multimedia: The MCALL project. Journal of Educational Multimedia and Hypermedia, 7, 71-89. 
Sotillo, S. (2000). Discourse functions and syntactic complexity in synchronous and asynchronous communication. Language Learning and Technology, 4, 82-119.

Stenson, N., Downing, B., Smith, J. \& Smith, K. (1992). The effectiveness of computer-assisted pronunciation training. CALICO Journal, 9, 5-19.

Sullivan, N., \& Pratt, E. (1996). A comparative study of two ESL writing environments: A computer-assisted classroom and a traditional oral classroom. System, 29, 491-501.

Thaipakdee, S. (1992). Relationships among writing quality, attitudes toward writing, and attitudes toward computers in a computermediated technical writing class for English as a foreign language students. Dissertation Abstracts International, A: The Humanities and Social Sciences, 53, 1135-A.

Thompson, A. D., Simonsen, M. R., \& Hargrave, C. P. (1992). Educational Technology: A Review of Research. Washington DC: Association for Educational Communications and Technology.

Verano, M. (1989). USAFA interactive study in Spanish. In W.F. Smith (Ed.), Modern technology in foreign language instruction (pp. 136-154). Lincolnwood, IL: National Textbook Company.

Walchowicz, K. A. and Scott, B. (1999). Software That Listens: It's Not a Question of Whether, It's a Question of How. CALICO Journal, 16, 253276.

Warschauer, M. (1995) (Ed.), Virtual connections: Online activities and projects for networking language learners. Honolulu, Hawaii: University of Hawaii Second Language Teaching and Curriculum Center.

Warschauer, M., Shetzer, H., \& Meloni, C. (2000). Internet for English teaching. Washington, DC: TESOL.

Weasenforth, D. , Meloni, C., \& Biesenbach-Lucas, S. (2005). Learner autonomy and course management software. In B. Holmberg, M. Shelley, \& C. White (Eds.). Distance education and language: Evolution and change (pp. 134-168). Clevedon, UK: Multilingual Matters.

White, L. (1987). Against comprehensible input: The input hypothesis and the development of L2 competence. Applied Linguistics, 8, 95-110. 


\section{Others References}

Auralog Inc. (2011). Tell me More.

Command Performance Language Institute. (1999). Live Action English Interactive.

DynEd International. (2005). Dynamic English.

EuroTalk Interactive. (2001). Talk Now! Talk More! World Talk (Instant Immersion).

EuroTalk Limited. (2000). Asterix - Learn English.

Fairfield Language Technology. (2010). Rosetta Stone English (American).

Heinle \& Heinle. (2009). Making Connections.

Language Publications Interactive, Inc. (2012). Who's Oscar Lake?

Pearson. (2012). ELLIS Academic.

Pearson/Longman. (2012). Longman English Interactive.

Pearson/Longman. (2005). Side-by-Side.

Protea Textware Pty. Ltd. (2011). Issues in English.

Techno-Ware, Inc. (2005). English Discoveries.

The Language Company. (2010). Learn to Speak English Deluxe.

Transparent Language. (2003). Learn English Now.

(Recebido em 13/01/14. Aceito em 14/04/14) 
